\title{
KESESUAIAN DAN PREFERENSI LIRIOMYZA HUIDOBRENSIS (BLANCHARD) (DIPTERA: AGROMYZIDAE) PADA BERBAGAI TUMBUHAN INANG
}

\author{
Purnomo $^{1}$, Aunu Rauf ${ }^{2}$, Soemartono Sosromarsono ${ }^{2}$, dan Teguh Santoso ${ }^{2}$
}

\begin{abstract}
Host suitability and the preference of Liriomyza huidobrensis (Blanchard) (Diptera: Agromyzidae) on different host plants. Potato leafminer, Liriomyza huidobrensis has become a major pest on highland vegetables since its invasion in Indonesia in 1994. The objectives of this research was to elucidate the level of suitability and the preference of $L$. huidobrensis on different host plant species. Research was conducted in Insect Ecology Laboratory, Department of Plant Pests and Diseases, Faculty of Agriculture-IPB. The result of laboratory experiments indicated that host plants showing the highest level of suitability (based on the intrinsic rate of increase, r) were potato (Solanum tuberosum), chinese cabbage (Brassica chinensis var. parachinensis), kacang endul (P. vulgaris), and snap bean (P. vulgaris). Low host suitability were found on cucumber (Cucumis sativus), tomato ( S. lycopersicum), wild radish (Nasturtium indicum) and a non-crop vegetation, galinggang (Galinsoga parviflora). There was consistency between suitability and host preference. The first four host plants mentioned above were preferred for feeding and laying eggs.
\end{abstract}

Key words: Liriomyza huidobrensis, host suitability

\section{PENDAHULUAN}

Lalat pengorok daun, Liriomyza huidobrensis (Blanchard) (Diptera: Agromyzidae), merupakan hama penting pada berbagai tanaman sayuran di berbagai negara (Spencer, 1973; Li, et al., 2007). Hama L. huidobrensis adalah hama yang bersifat polifag (Parrella, 1987). Survei yang dilakukan oleh Rauf et al. (1999; 2000) mendapatkan 50 spesies tumbuhan yang tergolong ke dalam 13 famili, termasuk berbagai tanaman bunga dan tumbuhan liar, sebagai inang. Hal ini menunjukkan bahwa lalat pengorok daun kentang dapat memanfaatkan berbagai tumbuhan inang sebagai makanan untuk hidupnya. Walaupun demikian, belum banyak diketahui tentang kesesuaian dan preferensi L. huidobrensis pada berbagai tumbuhan inangnya. Pada daerah pertanaman sayuran di dataran tinggi, jenis sayuran yang umum diusahakan di antaranya adalah kentang, tomat, kubis, caisin, kacang buncis, dan mentimun. Di tempat itu juga umumnya dapat dijumpai berbagai jenis tumbuhan liar yang dapat menjadi inang lalat pengorok daun. Keberadaan dan kelimpahan jenis tanaman inang yang sesuai pada skala ruang dan waktu tidak pelak lagi merupakan faktor yang mendukung perkembangan populasi hama ini di agroekosistem sayuran (Wei et al., 2000). Penelitian bertujuan untuk mengkaji tingkat kesesuaian dan preferensi L. huidobrensis pada berbagai jenis sayuran dan tumbuhan liar.

\section{METODE PENELITIAN}

Penelitian ini dilaksanakan di laboratorium ekologi serangga Departemen Proteksi Tanaman, Fakultas Pertanian-IPB, Baranangsiang, pada Januari 1999 hingga Juni 2000.

Penyiapan tumbuhan uji. Tumbuhan yang diuji adalah kacang buncis (Phaseolus vulgaris L.), kacang endul (P. vulgaris L.), caisin (Brassica chinensis L. var. parachinensis), tomat (Solanum lycopersicum L.), mentimun (Cucumis sativus L.), galinggang (Galinsoga parviflora Cav.), sawi tanah (Nasturtium indicum (L.)), dan kentang (Solanum tuberosum L.). Kacang buncis dan endul mewakili Famili Leguminosae, kentang dan tomat Solanaceae, mentimun mewakili Cucurbitaceae, caisin dan sawi tanah Brassicaceae, dan galinggang mewakili Compositae. Selain pertimbangan famili, galinggang dan sawi tanah dipilih untuk mewakili tumbuhan liar yang banyak tumbuh di pertanaman sayuran dataran tinggi (Everaarts, 1981).

Benih caisin, kacang buncis, mentimun, dan tomat diperoleh dari kios pertanian, sedangkan benih kentang dan kacang endul diperoleh dari petani

\footnotetext{
$\overline{1}$ Jurusan Proteksi Tanaman, Fakultas Pertanian, Universitas Lampung Jl. Prof. Soemantri Brodjonegoro No. 1 Bandar Lampung 35145

${ }^{2}$ Departemen Proteksi Tanaman, Fakultas Pertanian, Institut Pertanian Bogor, Jl. Kamper, Kampus Darmaga, Bogor 16680
} 
Pangalengan, Bandung. Galinggang dan sawi tanah diperoleh dengan memindahkan kedua tumbuhan liar ini dari lapanganan yang kemudian dipelihara pada pot. Galinggang dipindahkan saat tingginya sekitar 10 $\mathrm{cm}$ (sebelum berbunga), sedangkan sawi saat berukuran tinggi $5 \mathrm{~cm}$.

Penyiapan percobaan lama perkembangan dan sintasan. Untuk kepentingan percobaan ini benih atau tumbuhan liar cabutan ditanam dalam pot (tinggi $20 \mathrm{~cm}$, diameter atas $20 \mathrm{~cm}$, diameter bawah $17 \mathrm{~cm}$ ) yang berisi tanah steril dan diberi pupuk NPK $3 \mathrm{~g}$. Setelah benih atau cabutan ditanam, pot segera disungkup dengan kurungan plastik (tinggi $100 \mathrm{~cm}$, diameter $20 \mathrm{~cm}$ ). Bagian samping kurungan plastik diberi jendela (panjang $12 \mathrm{~cm}$, lebar $10 \mathrm{~cm}$ ) yang ditutupi kain kasa sebagai ventilasi. Kecuali mentimun yang ditanam tunggal, tumbuhan lainnya dipelihara dua tanaman per pot. Sebagai penunjang tanaman digunakan ajir bambu setinggi kurungan.

Infestasi $L$. huidobrensis ke dalam kurungan dilakukan pada saat tanaman kacang buncis dan kacang endul berumur 30 - 40 hari, kentang 40 hari, mentimun 20 - 30 hari, dan caisin, galinggang, serta sawi tanah berumur sekitar 20 hari.

Penyiapan percobaan keperidian dan preferensi. Benih atau tumbuhan liar cabutan ditanam pada pot berdiameter dan tinggi lima sentimeter. Kecuali tanaman kentang yang digunakan untuk percobaan ketika telah berumur 30 hst., tanaman lain digunakan ketika berumur sekitar 20 hst. Sebelum digunakan dalam percobaan, tanaman dipelihara dalam kurungan berdinding kain kasa (panjang $80 \mathrm{~cm}$, lebar $60 \mathrm{~cm}$, tinggi $100 \mathrm{~cm}$ ) agar terhindar dari serangan hama.

Lama perkembangan pradewasa. Sebelum percobaan dimulai disediakan terlebih dahulu imago L. huidobrensis yang berasal dari tanaman seledri dengan cara berikut. Daun seledri dengan gejala korokan larva L. huidobrensis dikumpulkan dari daerah pertanaman seledri di Ciherang-Cianjur dan kemudian dibawa ke laboratorium. Daun-daun tersebut diletakkan di dalam wadah plastik berbentuk silinder (diameter dan tinggi $25 \mathrm{~cm}$ ). Pada bagian atasnya diberi lubang (diameter $5 \mathrm{~cm}$ ), dan kemudian pada lubang tadi dipasang corong gelas secara terbalik. Pada leher corong ditempatkan cawan plastik (diameter $6 \mathrm{~cm}$, tinggi $5 \mathrm{~cm}$ ) yang berfungsi untuk menangkap imago lalat pengorok yang muncul. Bagian samping dan atas wadah plastik ditutup dengan kertas karbon berwarna hitam, dengan maksud agar imago yang muncul naik ke atas dan kemudian tertangkap dalam cawan.

Sebelum digunakan dalam percobaan, seluruh imago betina dan jantan yang muncul pada hari yang sama segera dimasukkan kedalam kurungan plastik yang berisi tumbuhan uji selama tiga hari, dengan maksud agar dalam selang waktu itu terjadi kopulasi.

Sepasang imago lalat yang berasal dari tanaman seledri dan telah berkopulasi tersebut dimasukkan ke dalam tumbuhan uji yang terkurung plastik (diameter $20 \mathrm{~cm}$, tinggi $100 \mathrm{~cm}$ ). Setelah 24 jam lalat dikeluarkan dari kurungan. Perlakuan pada setiap tumbuhan uji diulang enam kali.

Telur yang telah diletakkan oleh imago betina pada tumbuhan uji diamati perkembangannya sampai menjadi imago. Langkah pertama yang dilakukan adalah mencatat saat mulai terlihat gejala korokan pada daun, dengan bantuan kaca pembesar. Sejak telur diletakkan hingga munculnya gejala korokan dianggap sebagai lamanya periode telur. Langkah selanjutnya adalah mengamati korokan sampai terbentuk pupa. Pupa yang terbentuk dikumpulkan dan segera ditimbang dengan neraca Sartorius. Setelah ditimbang, pupa disimpan di dalam cawan berdiameter dan tinggi $5 \mathrm{~cm}$ hingga muncul menjadi imago. Pada percobaan ini pengamatan dilakukan terhadap stadia telur, stadia larva, stadia pupa, bobot pupa, persentase larva menjadi pupa, dan persentase pupa menjadi imago. Imago yang muncul dari tiap tumbuhan uji digunakan untuk percobaan lama hidup imago betina dan keperidian, seperti diuraikan di bawah ini.

Lama hidup imago betina dan keperidian. Sepasang imago yang berasal dari percobaan lama perkembangan pradewasa diinfestasikan ke dalam tumbuhan uji yang berdaun dua atau tiga helai dan tersungkup plastik (diameter $12 \mathrm{~cm}$, tinggi $40 \mathrm{~cm}$ ). Setelah satu hari, tumbuhan uji dikeluarkan dan diganti dengan tumbuhan uji yang baru, demikian tiap hari dilakukan sampai imago betina mati. Jika ada imago jantan mati, diganti dengan imago yang lain. Pengamatan dilakukan terhadap banyaknya telur yang diletakkan pada daun tumbuhan uji, dengan bantuan mikroskop. Percobaan diulang sebanyak 15 kali. 
Preferensi makan dan peneluran. Preferensi makan diukur berdasarkan banyaknya tusukan-makan yang terdapat pada setiap tumbuhan uji. Tumbuhan uji diupayakan memiliki luas daun yang hampir sama ( \pm $100 \mathrm{~cm}^{2}$ ). Pengukuran daun menggunakan kertas milimeter. Percobaan dilaksanakan dengan metode pilihan-bebas. Untuk maksud tersebut 40 ekor imago betina umur 1 hari asal seledri dimasukkan ke dalam kurungan berukuran $60 \mathrm{~cm} \times 60 \mathrm{~cm} \times 60 \mathrm{~cm}$. Ke dalam kurungan kemudian segera dimasukkan pot tumbuhan yang ditempatkan secara acak. Setelah 24 jam, tumbuhan dikeluarkan dari kurungan dan dengan bantuan mikroskop stereo banyaknya tusukan-makan yang terdapat pada tiap inang dihitung dan dicatat.

Percobaan preferensi peletakan telur dilaksanakan dengan prosedur yang sama dengan percobaan preferensi makan, kecuali imago yang digunakan adalah yang telah berumur tiga hari dan telah kawin. Kedua jenis percobaan preferensi ini masing-masing diulang sepuluh kali.

Parameter neraca kehidupan. Parameter neraca kehidupan diduga dengan menggabungkan informasi dari percobaan lama perkembangan dan sintasan pradewasa dengan informasi dari percobaan keperidian seperti yang dilakukan oleh Lysyk (2000). Usia sejak lahir hingga mati dihitung sebagai $\mathrm{x}_{\mathrm{t}}$ (masa perkembangan pradewasa + usia imago saat mati, $x$ ). Sintasan dari saat lahir hingga usia $\mathrm{x}_{\mathrm{t}}\left(\mathrm{l}_{\mathrm{xt}}\right)$ ditentukan sebagai hasil perkalian sintasan pradewasa dengan sintasan sejak imago muncul hingga berumur $\mathrm{x}$. Banyaknya keturunan betina yang dihasilkan oleh serangga betina pada umur $\mathrm{x}$ dinyatakan sebagai $\mathrm{m}_{\mathrm{xt}}$. Laju reproduksi bersih (Ro) dihitung sebagai $\sum \mathrm{l}_{\mathrm{xt}} \mathrm{m}_{\mathrm{xt}}$, nilai tengah masa generasi (T) dihitung sebagai $\Sigma$ $\mathrm{x}_{\mathrm{t}} \cdot \mathrm{l}_{\mathrm{xt}} \cdot \mathrm{m}_{\mathrm{xt}} / \mathrm{Ro}$, dan laju pertambahan intrinsik (r) dihitung menggunakan persamaan $\sum \mathrm{e}^{\mathrm{rxt}} \cdot \mathrm{l}_{\mathrm{xt}} \cdot \mathrm{m}_{\mathrm{xt}}=1$ (Birch, 1948; Lysyk 2000). Karena laju pertambahan intrinsik adalah suatu statistik komposit, yang telah memperhitungkan masa perkembangan pradewasa, keperidian, masa hidup imago, sintasan, dan nisbah kelamin (Messenger, 1964; Price, 1997), maka parameter ini dapat dijadikan kriteria yang tepat untuk menilai kesesuaian serangga terhadap tumbuhan inang.

Analisis data. Analisis ragam diterapkan untuk menguji pengaruh perbedaan tumbuhan inang terhadap lama perkembangan dan sintasan pradewasa, bobot pupa, lama hidup imago, keperidian, dan preferensi makan serta peletakan telur, dengan menggunakan program MINITAB 13.20 (MINITAB Inc., 2000). Pengujian perbedaan nilai tengah menggunakan uji jarak berganda Duncan .

\section{HASIL DAN PEMBAHASAN}

Lama perkembangan pradewasa, imago, dan keperidian. Lama perkembangan pradewasa $L$. huidobrensis dipengaruhi oleh jenis tumbuhan inang, begitu pula bobot pupa yang terbentuk (Tabel 1). Lama perkembangan telur pada kentang (2,62 hari), caisin (2,68 hari) dan buncis (2,74 hari) secara nyata lebih rendah dibandingkan pada tumbuhan uji lainnya yang mencapai lebih dari 3 hari $(F=11,10 ; d b=7$, 35 ; $\mathrm{P}<0,001)$. Lama perkembangan larva pada kentang (6,05 hari) dan caisin (6,14 hari) lebih singkat daripada galinggang (6,65 hari), sawi tanah $(6,69$ hari) dan tomat $(6,58$ hari) $(\mathrm{F}=2,24 ; \mathrm{db}=7,35 ; \mathrm{P}=$ 0,032 ). Sebaliknya, bobot pupa pada kentang, kacang endul, buncis dan caisin lebih berat $(\geq 0,67 \mathrm{mg})$ dibandingkan pada tumbuhan inang yang lain $(0,61$ $0,64 \mathrm{mg}) \quad(\mathrm{F}=6,59 ; \mathrm{db}=7,35 ; \mathrm{P}<0,001)$.

Persentase larva yang berhasil menjadi pupa tidak dipengaruhi oleh jenis tumbuhan inang ( $\mathrm{F}=0,92$ ; db 7, 35 ; $\mathrm{P}=0$,325) (Tabel 2), demikian juga persentase pupa yang berhasil menjadi imago $(\mathrm{F}=$ $1,17$; db 7, $35 ; P=0,205)$. Rataan persentase larva menjadi pupa berkisar 79,06 \% pada galinggang hingga 87,37 \% pada kacang endul, dan rataan persentase pupa menjadi imago berkisar 67\% (galinggang) hingga lebih dari 78\% (caisin, kentang, mentimun).

Jenis tumbuhan inang tidak mempengaruhi lama hidup imago betina $(\mathrm{F}=1,45 ; \mathrm{db}=7,35 ; \mathrm{P}=$ 0,189)(Tabel 2). Rataan lama hidup imago berkisar antara 6,95-7,65 hari. Sebaliknya, keperidian dipengaruhi oleh jenis tumbuhan inang. Rataan keperidian tertinggi (93,80 butir) terdapat pada lalat pengorok daun yang dibiakkan pada kentang, dan berbeda nyata $(\mathrm{F}=1,18 ; \mathrm{db}=7,98 ; \mathrm{P}=0,029)$ dengan yang dibiakkan pada galinggang, mentimun, sawi tanah dan tomat yang masing-masing dengan keperidian kurang dari 81 butir.

Preferensi makan dan peletakan telur. Jenis tumbuhan inang berpengaruh nyata terhadap kegiatan 
Tabel 1. Rataan lama perkembangan pradewasa dan bobot pupa ( \pm Galat Baku) L. huidobrensis pada berbagai tumbuhan inang

\begin{tabular}{|c|c|c|c|c|}
\hline \multirow{2}{*}{ Tumbuhan inang } & \multicolumn{3}{|c|}{ Rataan lama stadia (hari) } & \multirow{2}{*}{$\begin{array}{c}\text { Rataan bobot } \\
\text { pupa (mg) }\end{array}$} \\
\hline & Telur & Larva & Pupa & \\
\hline Caisin & $2,68 \pm 0,05$ a & $6,14 \pm 0,09$ a & $8,04 \pm 0,09 a b$ & $0,67 \pm 0,01$ a \\
\hline Galinggang & $3,39 \pm 0,06 \mathrm{~d}$ & $6,65 \pm 0,10 \mathrm{bc}$ & $8,92 \pm 0,12$ e & $0,61 \pm 0,01 \mathrm{~b}$ \\
\hline Kc. buncis & $2,74 \pm 0,07$ a & $6,28 \pm 0,07 a b$ & $8,25 \pm 0,11$ bc & $0,71 \pm 0,01 \mathrm{a}$ \\
\hline Kc. endul & $3,01 \pm 0,06 \mathrm{~b}$ & $6,30 \pm 0,07 \mathrm{abc}$ & $8,33 \pm 0,10$ bc & $0,69 \pm 0,01 \mathrm{a}$ \\
\hline Kentang & $2,62 \pm 0,07$ a & $6,05 \pm 0,08 \mathrm{a}$ & $7,91 \pm 0,10 \mathrm{a}$ & $0,70 \pm 0,01 \mathrm{a}$ \\
\hline Mentimun & $3,14 \pm 0,08$ bc & $6,30 \pm 0,07 \mathrm{ab}$ & $8,44 \pm 0,12 \mathrm{~cd}$ & $0,63 \pm 0,01 b$ \\
\hline Sawi tanah & $3,30 \pm 0,06 \mathrm{~cd}$ & $6,69 \pm 0,10$ с & 8,68 \pm 0,12de & $0,61 \pm 0,01 b$ \\
\hline Tomat & $3,15 \pm 0,07 \mathrm{~cd}$ & $6,58 \pm 0,09$ bc & $8,51 \pm 0,11 \mathrm{~cd}$ & $0,64 \pm 0,01 \mathrm{~b}$ \\
\hline $\mathrm{F}$ & 11,10 & 2,24 & 8,72 & 6,59 \\
\hline $\mathrm{P}$ & $<0,001$ & 0,032 & $<0,001$ & $<0,001$ \\
\hline
\end{tabular}

Keterangan : angka yang diikuti oleh huruf yang sama pada kolom yang sama tidak berbeda nyata menurut uji Duncan pada taraf nyata $5 \%$

Tabel 2. Persentase larva jadi pupa dan pupa jadi imago beserta lama hidup dan keperidian ( \pm Galat Baku) imago L. huidobrensis pada berbagai tumbuhan inang

\begin{tabular}{lcccc}
\hline $\begin{array}{l}\text { Tumbuhan } \\
\text { inang }\end{array}$ & $\begin{array}{c}\text { Persentase larva } \\
\text { jadi pupa (\%) }\end{array}$ & $\begin{array}{c}\text { Persentase pupa } \\
\text { jadi imago (\%) }\end{array}$ & $\begin{array}{c}\text { Rataan lama hidup } \\
\text { imago betina (hari) }\end{array}$ & $\begin{array}{c}\text { Rataan keperidian } \\
\text { (butir) }\end{array}$ \\
\hline Caisin & $82,79 \pm 0,36 \mathrm{a}$ & $78,66 \pm 2,13 \mathrm{a}$ & $7,65 \pm 0,38 \mathrm{a}$ & $83,87 \pm 2,98 \mathrm{ab}$ \\
Galinggang & $79,06 \pm 0,82 \mathrm{a}$ & $66,77 \pm 1,67 \mathrm{a}$ & $7,00 \pm 0,53 \mathrm{a}$ & $78,83 \pm 2,11 \mathrm{~b}$ \\
Kc. buncis & $83,37 \pm 1,43 \mathrm{a}$ & $76,39 \pm 2,02 \mathrm{a}$ & $7,96 \pm 0,43 \mathrm{a}$ & $86,93 \pm 2,21 \mathrm{ab}$ \\
Kc. endul & $87,37 \pm 1,02 \mathrm{a}$ & $70,55 \pm 3,15 \mathrm{a}$ & $8,00 \pm 0,45 \mathrm{a}$ & $88,27 \pm 2,82 \mathrm{ab}$ \\
Kentang & $82,39 \pm 1,95 \mathrm{a}$ & $78,65 \pm 1,59 \mathrm{a}$ & $8,07 \pm 0,30 \mathrm{a}$ & $93,80 \pm 2,82 \mathrm{a}$ \\
Mentimun & $84,94 \pm 2,88 \mathrm{a}$ & $79,84 \pm 2,75 \mathrm{a}$ & $7,23 \pm 0,50 \mathrm{a}$ & $78,93 \pm 2,47 \mathrm{~b}$ \\
Sawi tanah & $82,21 \pm 1,49 \mathrm{a}$ & $74,37 \pm 3,05 \mathrm{a}$ & $6,95 \pm 0,60 \mathrm{a}$ & $78,67 \pm 2,95 \mathrm{~b}$ \\
Tomat & $87,10 \pm 2,18 \mathrm{a}$ & $68,74 \pm 2,06 \mathrm{a}$ & $7,35 \pm 0,39 \mathrm{a}$ & $80,32 \pm 2,36 \mathrm{~b}$ \\
\hline $\mathrm{F}$ & 0,92 & 1,17 & 1,45 & 1,18 \\
\hline P & 0,325 & 0,205 & 0,189 & 0,029 \\
\hline
\end{tabular}

Keterangan : angka yang diikuti oleh huruf yang sama pada kolom yang sama tidak berbeda nyata menurut uji Duncan pada taraf nyata $5 \%$ 
makan dan peletakan telur oleh imago betina $L$. huidobrensis (Tabel 3). Rataan banyaknya tusukanmakan terbanyak pada buncis $(22,63)$, disusul kemudian pada kentang $(21,63)$, kacang endul $(19,18)$ dan caisin $(17,06)$, dan berbeda nyata dengan pada tumbuhan uji lainnya $(\mathrm{F}=30,52 ; \mathrm{db}=7,63$; $\mathrm{P}$ $<0,001$ ). Keempat tumbuhan ini (buncis, kentang, kacang endul, dan caisin) juga memiliki rataan kerapatan telur yang 2-3 kali lebih banyak dibandingkan pada tumbuhan uji yang lain ( $\mathrm{F}=26,36$; $\mathrm{db}=7,63 ; \mathrm{P}<0,001$ ).

Karena sebelum percobaan dimulai, luasan daun untuk tiap tanaman uji diupayakan sama, maka perbedaan kerapatan tusukan dan telur dapat dijadikan indikator preferensi lalat $L$. huidobrensis terhadap tumbuhan inang. Dalam hubungan ini, kacang buncis, kacang endul, kentang dan caisin lebih dipilih oleh lalat pengorok untuk kegiatan makan dan peletakan telur daripada tumbuhan inang lainnya.

Parameter neraca kehidupan. Nilai penduga berbagai parameter pertumbuhan populasi disajikan pada Tabel 4. Laju reproduksi bersih dan laju pertambahan intrinsik L. huidobrensis pada kentang adalah yang paling tinggi $(\mathrm{Ro}=19,4810, \mathrm{r}=0,1395)$, sedangkan lama generasinya paling singkat $(\mathrm{T}=$ 21,2859) dibandingkan pada tumbuhan inang lainnya. Hal ini menunjukkan bahwa kentang adalah tumbuhan inang yang paling sesuai bagi kehidupan
L. huidobrensis. Tumbuhan inang lain yang dapat mendukung laju pertumbuhan populasi lalat pengorok daun yang cepat adalah caisin $(r=0,1270)$ dan kacang endul $(r=0,1250)$.

Hasil penelitian menunjukkan bahwa jenis tumbuhan inang berpengaruh terhadap berbagai parameter kehidupan L. huidobrensis. Di antara parameter itu adalah lama perkembangan telur, larva dan pupa, bobot pupa, dan keperidian. Berdasarkan kelima parameter tadi, tampaknya kentang, buncis, kacang endul, dan caisin menyediakan sumberdaya makanan yang lebih baik bagi $L$. huidobrensis. Pengaruh perbedaan jenis tumbuhan inang terhadap kehidupan L. huidobrensis juga dilaporkan oleh peneliti lain (Hammad \& Nemer, 1999; Parrella \& Bethke, 1984), dan terhadap spesies lain dari Liriomyza seperti L. trifolii (Zoebisch \& Schuster, 1987; Parrella et al., 1983) dan L. sativae (Parkman et al., 1989).

Dalam penelitian ini ditunjukkan bahwa kentang, buncis, kacang endul, dan caisin lebih dipilih oleh lalat pengorok daun, seperti ditunjukkan oleh banyaknya tusukan-makan dan banyaknya telur yang diletakkan. Berbagai studi mengungkapkan bahwa pemilihan inang oleh imago Liriomyza dipengaruhi oleh banyak faktor. Fagoonee \& Toory (1983) melaporkan bahwa pemilihan inang oleh L. trifolii tergantung pada umur fisiologi daun. Selanjutnya dilaporkan bahwa L. trifolii lebih menyukai tumbuhan

Tabel 3. Rataan banyaknya tusukan dan banyaknya telur yang diletakkan ( \pm Galat Baku) pada berbagai tumbuhan inang

\begin{tabular}{lcc}
\hline $\begin{array}{c}\text { Tumbuhan } \\
\text { Inang }\end{array}$ & $\begin{array}{c}\text { Kerapatan tusukan } \\
\left(\text { tusukan/ } \mathrm{cm}^{2}\right)\end{array}$ & $\begin{array}{c}\text { Kerapatan telur } \\
\left(\mathrm{butir} / \mathrm{cm}^{2}\right)\end{array}$ \\
\hline Kacang buncis & $22,63 \pm 1,22 \mathrm{a}$ & $0,96 \pm 0,05 \mathrm{ab}$ \\
Kentang & $21,08 \pm 0,66 \mathrm{ab}$ & $1,08 \pm 0,05 \mathrm{a}$ \\
Kacang endul & $19,18 \pm 0,81 \mathrm{bc}$ & $1,01 \pm 0,05 \mathrm{ab}$ \\
Caisin & $17,06 \pm 0,62 \mathrm{c}$ & $0,95 \pm 0,02 \mathrm{ab}$ \\
Galinggang & $12,09 \pm 1,29 \mathrm{~d}$ & $0,55 \pm 0,04 \mathrm{c}$ \\
Mentimun & $11,45 \pm 1,56 \mathrm{~d}$ & $0,46 \pm 0,06 \mathrm{~cd}$ \\
Tomat & $10,56 \pm 0,78 \mathrm{~d}$ & $0,50 \pm 0,05 \mathrm{c}$ \\
Sawi tanah & $6,25 \pm 1,16 \mathrm{e}$ & $0,31 \pm 0,06 \mathrm{~d}$ \\
\hline F & 30,52 & 26,36 \\
P & $<0,001$ & $<0,001$ \\
\hline
\end{tabular}

Keterangan : angka yang diikuti oleh huruf yang sama pada kolom yang sama tidak berbeda nyata menurut uji Duncan pada taraf nyata $5 \%$ 
Tabel 4. Parameter neraca kehidupan $L$. huidobrensis pada berbagai tumbuhan inang

\begin{tabular}{lccc}
\hline Tumbuhan inang & Ro & $\mathrm{T}$ & $\mathrm{r}$ \\
\hline Kentang & 19,4810 & 21,2859 & 0,1395 \\
Kacang endul & 17,2459 & 22,7760 & 0,1250 \\
Kacang buncis & 17,1388 & 23,7741 & 0,1195 \\
Caisin & 15,7220 & 21,6930 & 0,1270 \\
Mentimun & 14,5271 & 23,1689 & 0,1155 \\
Tomat & 14,3650 & 24,5603 & 0,1090 \\
Sawi tanah & 14,2162 & 24,3585 & 0,1090 \\
Galinggang & 12,0102 & 23,4505 & 0,1060 \\
\hline
\end{tabular}

inang yang memiliki kandungan nitrogen yang tinggi (Minkenberg \& Fredrix, 1989; Minkenberg \& Ottenheim, 1990). Sementara itu, kerapatan trikom dan eksudat yang dihasilkannya juga dapat mempengaruhi pemilihan inang oleh lalat pengorok daun (Fagoonee \& Toory 1983; Knodel-Montz et al., 1985). Wei et al. (2000) menyatakan bahwa pemilihan inang oleh imago $L$. huidobrensis berkorelasi positif dengan kandungan air yang tinggi, dan berkorelasi negatif dengan ketebalan epidermis serta kerapatan jaringan pagar dan bunga karang. Selain itu, kandungan senyawa fenol dalam tumbuhan inang dilaporkan menentukan sifat antisenosis terhadap L. brassicae (Ipe \& Sadaruddin, 1984).

Secara keseluruhan, hasil penelitian menunjukkan adanya konsistensi antara parameter kesesuaian dan preferensi inang dengan parameter neraca kehidupan. Tumbuhan inang yang lebih sesuai dan lebih dipilih (kentang, buncis, kacang endul, caisin) seperti disebutkan di atas menunjang pertumbuhan populasi yang lebih cepat seperti terlihat dari nilai $r$ (Tabel 4). Tampaknya imago betina L. huidobrensis lebih memilih jenis tumbuhan inang yang mampu mendukung kebugaran keturunannya, yang mengisyaratkan ciri pra-adaptif yang dimiliki oleh lalat pengorok daun. Nilai r yang paling tinggi diperlihatkan oleh $L$. huidobrensis yang dipelihara pada kentang. Hal ini mungkin dapat menjelaskan mengapa populasi dan serangan $L$. huidobrensis di lapangan umumnya selalu tinggi pada pertanaman kentang.

Karena beragamnya tumbuhan inang yang berada di lapangan, lalat pengorok daun dipastikan dapat beralih dari satu tumbuhan ke tumbuhan inang lainnya. Oleh karena itu, preferensi peletakan telur seperti yang terjadi di laboratorium mungkin tidak selalu sejalan dengan yang berlangsung di lapangan, dan secara umum akan dipengaruhi oleh persebaran dan kelimpahan relatif dari setiap tumbuhan inang. Sebagai contoh pada saat kebanyakan petani menanam kentang, populasi lalat diperkirakan lebih memilih tanaman ini. Akan tetapi, jika inang terbaik sulit diperoleh maka lalat dapat memilih hidup pada tumbuhan inang lain yang ada di sekitar pertanaman.

Dari segi praktis, hasil penelitian yang dilakukan memberikan sumbangan bagi pemilihan tumbuhan inang untuk tujuan pembiakan massal L. huidobrensis di laboratorium. Tumbuhan inang dengan tingkat preferensi dan kesesuaian serta menunjang nilai $r$ yang tinggi sesuai untuk digunakan dalam kegiatan pembiakan massal lalat pengorok daun. Karena pemeliharaannya lebih mudah dan daunnya lebih lebar, kiranya caisin merupakan jenis tumbuhan inang yang tepat untuk keperluan pembiakan massal L. huidobrensis.

\section{SIMPULAN}

Tanaman kentang, kacang buncis, kacang endul, dan caisin lebih dipilih oleh dan lebih sesuai bagi kehidupan $L$. huidobrensis dibandingkan tanaman tomat, mentimun, galinggang, dan sawi tanah. Nilai laju pertambahan intrinsik (r) L. huidobrensis yang tinggi pada tanaman kentang $(0,1395)$ berperan besar dalam menunjang tingginya populasi dan serangan lalat pengorok daun pada pertanaman kentang di lapangan. Caisin (nilai $\mathrm{r}=$ 0,1270 ) sesuai untuk digunakan dalam pembiakan massal lalat pengorok daun di laboratorium. 


\section{DAFTAR PUSTAKA}

Birch, L.C. 1948. The intrinsic rate of natural increase of an insect population. J. Anim. Ecol. 17: $15-26$.

Everaarts, A.P. 1981. Weeds of vegetables in the highlands of Java. Jakarta: Horticultural Research Institute.

Fagoonee, I. \& V. Toory. 1983. Preliminary investigations of host selection mechanisms by the leafminer Liriomyza trifolii. Insect Sci. Appl. 4: 337 - 341.

Hammad, E.M.A.F. \& N.M. Nemer. 2000. Population densities, spatial pattern and development of the pea leafminer (Diptera: Agromyzidae) on cucumber, swisschard and bean. J. Agric. Sci. Cambridge 134: 61 - 68.

Ipe, M. \& M. Sadaruddin. 1984. Infestation and host specifity of Liriomyza brassicae Riley and the role of phenolic compounds in host plant resistance. Entomol. 9: 265 - 270.

Knodel-Montz, J.J., R.E. Lyons, \& S.L. Poe. 1985. Photoperiod affects Chrysanthemum host plant selection by leafminers (Diptera: Agromyzidae). Hortscience 20: 708 - 710.

Li, H.H., C. Bing, \& K. Le. 2007. Impact of mild temperature hardening on thermotolerance, fecundity, and Hsp gene expression in Liriomyza huidobrensis. J. Insect Physiol . 53: 1199-1205

Lysyk, T.J. 2000. Relationship between temperature and life history parameters of Muscidifurax raptor (Hymenoptera: Pteromalidae). Environ. Entomol. 29(3): 596 -605.

Messenger. 1964. Use of life tables in a bioclimatic study of an experimental aphid- braconids wasp host-parasitic system. Ecology 45: 110131

Minitab Inc. 2000. MINITAB 13.20 Statistical software.
Minkenberg, O.P.J.M. \& J.J.W. Ottenheim. 1990. Effects of leaf nitrogen content of tomato plants on preference and performance of a leafmining fly. Oecologia 83: 291 - 298.

Minkenberg, O.P.J.M. \& M.J.J. Fredrix. 1989. Preference and performance of an herbivorous fly, Liriomyza trifolii (Diptera; Agromyzidae) on tomato plants differing in leaf nitrogen. Ann. Entomol. Soc. Am. 82: 350 - 354.

Parkman, P., J.A. Dusky, \& V.H. Waddil. 1989. Biological studies of Liriomyza sativae (Diptera: Agromyzidae) on castor bean. Environ. Entomol.18(5): 768 - 772.

Parrella, M,P. 1987. Biology of Liriomyza. Аnпu. Rev. Entomol. 32: 201 - 224.

Parrella, M,P. \& J.A. Bethke. 1984. Biological studies of Liriomyza huidobrensis (Diptera: Agromyzidae) on chrysanthemum, aster, and pea. J. Econ. Entomol. 77: 342 - 345.

Parrella, M.P., K.L. Robb, \& J.A. Bethke. 1983. Influence of selected host plants on the biology of Liriomyza trifolii (Diptera: Agromyzidae). Ann. Entomol. Soc. Amer. 76: 112-115.

Price, P.W. 1997. Insect Ecology (Third Edition). John Willey \& Sons. New York.

Rauf A., I.S. Harahap, \& H. Zakia. 1999. Hama pengorok daun: tantangan baru bagi agribisnis bunga di Indonesia. Makalah disajikan pada Workshop Florikultura II, Bogor, 12 Mei 1999. $8 \mathrm{~h}$.

Rauf A., B.M. Shepard, \& M.W Johnson. 2000. Leafminer in vegetables, ornamental plants and weeds in Indonesia: surveys of host crops, species composition and parasitoids. Int J Pest Manage. 46 (4): 257 - 266.

Spencer K.A. 1973. Agomyzidae (Diptera) of Economic Importance. Dr. W Junk BV. The Hague. 
Wei Jianing, Li Zou, Rongping Kuang, \& Liping He. 2000. Influence of leaf tissue structure on host feeding selection by pea leafminer Liriomyza huidobrensis (Diptera: Agromyzidae). Zool. Studies 39 (4): 295 - 300.
Zoebisch T.G. \& D.J. Schuster. 1987. Suitability of foliage of tomatoes and three weed hosts for oviposition and development of Liriomyza trifolii (Diptera: Agromyzidae). J. Econ. Entomol. 80: 758 -762. 